DOI 10.37882/2223-2982.2021.08.31

\title{
СРАВНИТЕЛЬНЫЙ АНАЛИЗ ПЕРЕВОДА АВТОРСКИХ ОККАЗИОНАЛИЗМОВ НА МАТЕРИАЛЕ РОМАНА-АНТИУТОПИИ ДЖ. ОРУЭЛЛА «1984»
}

\section{COMPARATIVE ANALYSIS OF THE TRANSLATION OF THE AUTHOR'S OCCASIONALISMS BASED ON THE DYSTOPIAN NOVEL «1984» BY J. ORWELL}

A. Pushkina

L. Krivoshlykova K. Shestakova

Summary: The article is devoted to a comparative analysis of the methods of translation of the author's occasionalisms in the novel «1984» by J. Orwell. Ewo Russian-language translations of the novel were studied, one of which was made by V. Golyshev, the other - by V. Nedoshivin and D. Ivanov. The results of the analysis of the translation of occasionalisms showed that the most frequent methods are calques, analogue and descriptive translations, and translation occasionalisms. However, in a number of cases, the choice of translation solutions does not coincide in both Russian versions of the novel.

Keywords: author's occasionalism, translation occasionalism, nonequivalent vocabulary, translation techniques, equivalence in translation, adequacy in translation.
Пушкина Анна Владимировна

К.п.н., дочент, Российский университет дружбы народов

(2. Москва)

pushkina4@yandex.ru

Кривошлыкова Людмила Владимировна

К.ф.н., дочент, Российский университет дружбы народов

(2. Москва)

Ivk1404@mail.ru

Шестакова Ксения Александровна переводчик, радио studio 21 (г. Красногорск) xenia.shestackowa@yandex.ru

Аннотация: Статья посвящена сравнительному анализу способов перевода авторских окказионализмов в романе Дж.Оруэлла «1984». Материалом исследования послужили два русскоязычных перевода, один из которых выполнен В.Голышевым, другой - Д. Ивановым и В. Недошивиным. Результаты проведенного анализа перевода окказионализмов показали, что наиболее частотными приемами являются калькирование, переводческие окказионализмы и аналоговый и переводы. Однако в целом ряде случаев выбор переводческих решений не совпадает.

Ключевые слова: авторский окказионализм, переводческий окказионализм, безэквивалентная лексика, переводческие приемы, эквивалентность перевода, адекватность перевода.
$\mathrm{P}$ абота над художественными произведениями ставит перед переводчиками сложные задачи. Перед ними возникает необходимость максимально точно передать замысел автора, особенности стиля языка и атмосферу всего произведения. Иногда задача переводчика усложняется еще и тем, что в тексте присутствуют искусственно созданные слова - окказионализмы.

Материалом исследования послужил роман-антиутопия «1984», автором которого является Джордж Оруэлл [8], и его переводы, один выполнен В. Голышевым [5], другой - Д. Ивановым и В. Недошивиным [6].

Актуальность исследования обусловлена тем, что впервые предпринимается попытка сравнить перевод авторских окказионализмов Дж. Оруэлла на русский язык и классифицировать их по способу перевода.

Живой язык, как известно, постоянно развивается и изменяется, а самым подвижным элементом в системе языка является его словарный состав. Перемены в общественной жизни, развитие производства и технологий неизбежно приводят к изменению в словаре. Динамика языка наиярчайшим образом прослеживается в процессе возникновения новых слов. При этом, обогащение лексической системы языка может проходить как с помощью возникновения новых слов, так и благодаря приобретению словом нового значения.

Первоначально за всеми новыми словами был закреплен термин «неологизм». Однако в современном языкознании не существует единства мнений относительно лингвистического статуса неологизмов и окказионализмов. А.Г. Лыков предложил критерии, согласно которым новые слова можно отнести к той или иной категории:

1. время появления слова;

2. наличие - отсутствие конкретного творца;

3. ощущение - неощущение новизны слова;

4. вхождение - невхождение в язык $[4, c .95]$.

В.С. Виноградов, В свою очередь, отмечает, что неологизмы призваны выражать коммуникативную потребность общества, словесно обозначить новые предметы, явления, факты, понятия и т.Д., в то время как окказионализмы, являясь фактами речи, нацелены на выражение экспрессивно-эмоциональных новшеств, используемых 
индивидуумом [2]. Окказиональные слова - достояние речи. Они всегда экспрессивны, создаются конкретным автором, порождаются целями высказывания и контекстом, с которым связаны и вне которого обычно не воспроизводятся [2, с.152]. Они выполняют «характеристическую», а не номинативную функцию, в отличие от неологизмов [2, с. 153]. Еще одной отличительной чертой окказионализмов можно считать их привязанность к конкретному создателю. Поэтому окказиональные слова часто называют «авторскими» или «индивидуальными». Каждый автор стремится выразить яркость создаваемого образа, придумывает возможность одним емким словом заменить обычное слово или даже целое словосочетание и, с этой целью, использует нетипичные, уникальные методы словотворчества, которые с трудом поддаются типологическому описанию. Ведь именно благодаря такому новаторству, слово лучше запоминается и становится «изюминкой» всего произведения автора, с одной стороны, а с другой стороны, переводчик сталкивается со сложной, но интересной задачей - перевести, на первый взгляд, непереводимое, так как окказионализмы можно отнести к безэквивалентной лексике.

Перевод безэкивалентной лексики, в целом, и окказионализмов, в частности, - это всегда вызов для переводчика.

Наиболее распространенными приемами перевода нестандартных лексических элементов исходного текста, согласно Л.С. Бархударову, являются:

1. Транслитерация и транскрипция.

При переводческая транскрипции передается звуковая форма слова. Например: «know-how»«ноу-хау» [1, с.97].

При транслитерации передается графическая (буквенная) форма слова. Например: « General Motors» - «Дженерал Моторс» [1, с.97].

2. Калькирование.

Данный способ представляет собой передачу безэквивалентной лексики путем замены «морфем или слов в составе устойчивых выражений их прямыми лексическими соответствиями в переводящем языке». Например: «brain-drain» - «утечка мозгов» [1, с.99].

3. Аналог (приближенный перевод) предполагает подбор ближайшей по значению лексической единицы в переводящем языке. Например: «душегрейка» - «vest» [1, с.101].

4. Описательный перевод, который имеет место в тех случаях, когда безэквивалентная единица оригинала мало известна реципиенту перевода.

5. Трансформационный перевод.

Трансформационный перевод представляет собой передачу реалии при помощи какой-либо лексической, грамматической или стилистической трансформации.
Именно на основе представленной классификации приемов перевода безэквивалентной лексики мы проведем сравнительный анализ перевода авторских окказионализмов Дж. Оруэлла в романе «1984».

Приемы, предложенные Л.С. Бархударовым, довольно часто используются переводчиками. Однако нередко переводчики вынуждены и сами прибегнуть к словотворчеству, пытаясь воссоздать оригинал в переводящем языке. Именно так и появляются переводческие окказионализмы, которые В.С. Виноградов называл «собственно-переводческими лексическими окказионализмами», создаваемые переводчиком «в соответствии со смыслом и функцией индивидуальноавторских слов оригинала сообразно контексту подлинника и перевода, путем использования различных моделей словообразования» [2, с.60].

С целью выявления конечного значения окказионализма переводчики применяют компонентный анализ. Метод компонентного анализа представляет собой исследование содержательной стороны значимых единиц языка, с целью разложения значений на минимальные семантические составляющие - семы [3, с.27]. Проведение данного анализа позволяет установить все значение, включенные в окказионализм.

Роман-антиутопия «1984» был написан Дж. Оруэллом в 1949 году и описывает фантастическое общество выдуманной автором страны Океании, в котором функционирует собственный язык - новояз (newspeak). Новояз является искусственно разработанным официальным языком Океании. События, описываемые в романе происходят предположительно в 1984 году. Большая часть населения все еще изъясняется в основном на литературном английском языке (староязе), однако к 2050 году новояз должен был полностью заменить его. Все слова в новоязе при любой возможности пытались сократить. Как правило, слово новояза состояло из двух или трех слогов, что делало речь людей отрывистой, торопливой и монотонной. Задача состояла в том, чтобы сделать речь - в особенности такую, которая касалась идеологических тем, - по возможности независимой от сознания [7, с.100]. Вот почему перевод авторских окказионализмов Оруэлла является сложной задачей для переводчика - необходимо максимально точно передать все оттенки смыслов, заключающихся в окказиональных словах. При этом, все переводимые окказионализмы в своей совокупности должны соответствовать единому стилю новояза, должны передавать всю атмосферу произведения.

Перед тем как приступить непосредственно к анализу переводов авторских окказионализмов в романе Дж. Оруэлла «1984», приведем классификацию слов новояза с точки зрения способа их создания. 
Большинство слов новояза образованы путем слияния двух существующих в английском языке слов, представляющих собой различные части речи.

Чаще всего окказионализмы в романе были образованы путем сложения:

- существительное + существительное (facecrime (face+crime);

- существительное + прилагательное: ownlife (own+life);

- существительное + глагол: duckspeak (duck+ speak);

- глагол + глагол: speakwrite (speak+write);

- прилагательное+глагол:doublethink(double+think);

- прилагательное + прилагательное: blackwhite (black+white).

Кроме того, в романе встречаются окказионализмы, созданные путем контаминации, т.е. несколько слов были объединены в одно, при этом одно из них или все слова являлись сокращениями: ficdep (Fiction Department).

В грамматике новояза были введены новые префиксы, а также уже существующие префиксы стали обладать новым значением. Они могли добавляться к любым словам, определенным образом изменяя их значение. Например: приставка -un служит для придания слову противоположенного значения и используется с любой частью речи (uncold, unlight, undark, unperson, ungood, unproceed).

Определение способов создания окказионализмов, приведенных в оригинальном тексте, и деление их на составляющие поможет нам выполнить более точный анализ их русскоязычных эквивалентов. Ведь как было сказано ранее, сама форма окказионализма несет определенный смысл и чрезвычайно важна для понимания авторского замысла. Помимо этого, переводчик должен меть в виду следующие характерные особенности выдуманного языка романа:

1. слово должно иметь один четкий и ясный смысл;

2. слово должно состоять из 2-3 слогов;

3. составное слово должно произноситься легко.

Самым распространенным способом перевода окказионализмов в романе стал способ калькирования. Применение калькирования при переводе объясняется наличием у морфем, основ и слов исходного языка системных соответствий в переводящем языке и их способностью передать дополнительное коннотативное значение. Рассмотрим подробнее примеры переводов, выполненных с помощью данного способа:

«BВ»- является сокращенным обозначением «Big Brother», главы государства Океании. Стоит отметить, что само словосочетание «Big Brother» было переведено по-разному.
В переводе В. Голышева: «Старший брат». В этом случае переводчик воспользовался не основным значением «большой», а менее употребительным - «старший». Тем самым можно прийти к заключению, что переводчик хотел показать превосходство Брата, его степень величия над остальными людьми. Соответственно, сокращение «ВВ» было переведено как «СБ»

В переводе Д. Иванова и В. Недошивина: используется значение слова «big»- «большой». Перевод был выполнен буквально, возможно из-за многочисленных отсылок в произведении об огромных плакатах с лицом Большого Брата, развешанных по всей Океании. Следовательно, в данном переводе сокращение выглядело иначе- «ББ».

«Facecrime». Любая мимика или взгляд, наводящий на мысль о том, что тебе есть, что скрывать, бормотание себе под нос, скептическое выражение лица расценивалось в Океании как недопустимое действие.

В. Голышев перевел данное слово как лицепреступление. А Д. Иванов и В. Недошивин создают собственный окказионализм, созвучный со словом «преступник». К тому же, переведенный окказионализм имеет более краткую форму, нежели «лицепреступление», что в большей степени соответствует стилю новояза.

«Memory holes»- система труб в отделе литературы, где уничтожались все компрометирующие партию документы, а также имена когда-либо существовавших людей. Они работали по типу пневматических труб. В. Голышев предлагает вариант гнезда памяти, в то время как Д. Иванов и В. Недошивин - дыры памяти, что, на наш взгляд, лучше отражает игру слов, задуманную автором: в буквальном смысле, данная система представляла собой дыры и, в переносном смысле- в них выбрасывались важные документы, навсегда уничтожавшие доказательства фальсификации, записи об исторических событиях и упоминания о людях, когда-либо живших на земле, что влекло за собой, своего рода «дыры в памяти» или, как принято говорить, «пробелы в памяти». Важно подчеркнуть, что, пользуясь тем же самым приемом при переводе морфем переводчик используют синонимы, например:

«Artsem» (artificial insemination). В Океании существовала специальная организация - Молодежный антиполовой союз, проповедовавший полное целомудрие для обоих полов. Зачатие должно было происходить искусственно в общественных пунктах. В переводе В. Голышева - искос (искусственное осеменения). В переводе Д. Иванова и В. Недошивина - искплод (искусственное оплодотворение).

Аналогичную ситуацию мы наблюдаем с переводом 
окказионализма «Јоусатр» (forced-labor camp). В переводе В. Голышева - радлаг (лагерь радости, т. е. каторжный лагерь). В переводе Д. Иванова и В. Недошивина - восторглаг (исправительно-трудовой лагерь).

В обоих случаях переводчики используют прием калькирования, но для передачи морфем используют синонимы одного и того же слова: осеменение, оплодотворение; радость, восторг.

Также, при переводе Miniplenty (The Ministry of Plenty) В. Голышев предлагает вариант минизо (Министерство Изобилия), а Д. Иванов и В. Недошивин - Мини-много. Отметим, что Дж. Оруэлл использует игру слов, сокращая слово «Ministry» до «Mini», что придает окказионализму совершенно новое значение - минимальный, незначительный, мало. Выбор калькирования как способа перевода, использованного переводчиками в данном случае, можно считать удачным, так как приставка «мини» знакома и понятно русскоязычным читателям и вызывает аналогичные ассоциации.

В некоторых случаях переводчики прибегали к приему транскрипции/транслитерации.

Так, с помощью транскрипции слово «Prole" в обоих переводах было передано путем аналогичного сокращения от слова «пролетариат» - «прол».

А при переводе слова «Versificator» - специальная машина, производящая литературу и музыку для масс, - авторы переводов воспользовались приемом транслитерации.

Описание также считается не менее эффективным способом перевода окказионализмов. Например, при переводе слов «Thoughtcrime/ thoughtcriminals» В.Голышев снова придерживается приема калькирования ("мыслепреступление» /»мыслепреступники»), а Д. Иванов и В. Недошивин отдают предпочтение приему описания в обоих случаях («преступление мысли /»преступники мысли»).

В ряде случаев уместен способ перевода с помощью аналога.

Согласно онлайн словарю «Cambridge Dictionary», «Mouthpiece» -- это часть телефона, музыкального инструмента или любого другого устройства, которая прикладывается к губам. В обоих версиях перевода романа, переводчики перевели данное устройство с помощью аналога - «микрофон». Однако в том же словаре есть и второе значение данного слова:" a person or a newspaper that only expresses the opinions of one particular organization" [10]. Второе значение выражает скрытый смысл, который хотел донести Дж. Оруэлл. Автор не случайно выбрал данное слово. Ведь именно через это устройство писались новости, освещающие действия одной лишь партии и только в положительном свете, опровергающие очевидные факты. Однако такую тонкость передать русскоязычному читателю представляется практически невозможным.

«The Physical Jerks» - ежедневные утренние физические упражнения, выполняемые в обязательном порядке перед "телекраном" партийными жителями Океании. Слово также единогласно было переведено с помощью аналога «физзарядка».

Большинство слов делового жаргона новояза было переведено также с помощью аналога. Например,

«Dayorder»: в переводе В. Голышева - "наказ", в переводе Д. Иванова и В. Недошивина - "приказ".

«Fullwise»: в переводе В. Голышева - “сквозь", в переводе Д. Иванова и В. Недошивина - "полностью".

Самым интересным, на наш взгляд, является прием создания так называемого переводческого окказионализма. Именно здесь проявляется творческий потенциал переводчика, его понимание художественного замысла автора.

Приведем несколько примеров.

«Speakwrite» - машина, записывающая речь под диктовку.

Если В. Голышев применяет калькирование ("речепис"), то Д. Иванов и В. Недошивин используют переводческий окказионализм - «диктограф» по аналогии с диктофоном, который не позволяет им передать замысел автора, а именно - новые технологии будущего.

Похожая ситуация происходит и в следующем примере:

«Telescreen» - аппарат, устроенный по типу телевизора, работающий на прием и на передачу изображения. Он был установлен в каждом доме члена партии, что позволяло круглые сутки вести наблюдение за ними. В. Голышев переводит окказионализм с помощью калькирования. Слово «telescreen» представляет собой два объединенных слова «television» и «screen». Вместо существующего в русском языке слова «телеэкран» переводчик вводит новое слово «телекран». А в переводе Д. Иванова и В. Недошивина опять утерян фактор новизны ("монитор").

Рассмотрим еще несколько примеров создания переводческих окказионализмов. Слово «duckspeak» (буквально - утиная речь). Дж.Оруэлл сравнивает речь приверженцев ангсоца, повторяющих нелепые, зача- 
стую абсурдные положения партии, не задумываясь над их смыслом. Партия предполагала, что, в конце концов, членораздельная речь будет рождаться непосредственно в гортани, без участия высших нервных центров.

В. Голышев использует свой окказионализм - «речекряк», который в полной мере передает авторское негативное отношение к бессмыслице говоримого, к слепому повтору навязываемых государством мыслей.

В переводе Д. Иванова и В. Недошивина мы находим слово «раскрякаться», что тоже является примером авторского окказионлаизма, который, по всей видимости, был придуман по аналогии с русским словом «раскудахтаться», имеющее схожее значение - говорить долго, бестолково и взволнованно [9].

Однако это был не единственный вариант перевода этого слова. На страницах романа в переводе Д. Иванова и В. Недошивина, в зависимости от ситуации и структуры предложения, встречались следующие варианты перевода слова «duckspeak»: «уткоречь», “выкрякивались», "уткоречер", которые были переведены с помощью калькирования и переводческих окказионализмов

\section{соответственно.}

«Crimestop» - умение во время остановить свои размышления: не видеть аналогий и не замечать логических ошибок, пресекать все еретические мысли.

В переводе В. Голышева - «самостоп». Переводческий окказионализм хоть и не совпадает по форме с оригинальным, тем не менее, доносит до читателя всю суть слова.

В переводе Д. Иванова и В. Недошивина - « преступстоп» (переведено с помощью калькирования).

Таким образом, в нашей рассмотрели способы перевода одного из самых сложных вариантов безэквивалентной лексики, а именно - авторских окказионализмов.

Сравнивая приведенные переводы, можно сделать вывод, что перевод авторских окказионализмов - весьма творческий процесс. Нашей целью было выявить не лучший перевод, а всевозможные способы передачи такого пласта лексики. Оба варианта перевода романа, выполненных специалистами, чьи мастерство и талант не вызывают сомнений, донесли до читателей суть задумки автора, передали стиль и особенности выдуманного языка.

\section{ЛИТЕРАТУРА}

1. Бархударов Л.С. Язык и перевод (Вопросы общей и частной теории перевода). - Изд.5. - М., Ленанд, 2016. - 240 с.

2. Виноградов В.С. Введение в переводоведение (общие и лексические вопросы). — М.: Издательство института общего среднего образования РА0, 2001. $-224 C$.

3. Кабанова И.Н. Основы лексикологии. 2-ое издание, дополненное. - Нижний Новгород: ФГБОУ ВПО «НГЛУ», 2013. - 168 с.

4. Лыков А.Г. Современная русская лексикология (русское окказиональное слово). М. Высшая школа. 1976. - 120 с.

5. Оруэлл Дж. 1984 (пер. с англ. В. Голышева). - М: Издательство: АCT, Neoclassic, 2013. - 320 c.

6. Оруэлл Дж.: 1984 (пер. с англ Д. Иванова, В. Недошивина). Том І. - Пермь: Капик, 1992. - 304 с.

7. Сдобников В.В., Петрова 0.В. Теория перевода. - М.: АСТ, 2008. - 448 с.

8. Orwell G.1984. - Signet classics, 2015. C. 328

9. https://dic.academic.ru/dic.nsf/ushakov/1001566

10. https://dictionary.cambridge.org/dictionary/english/mouthpiece

○ Пушкина Анна Владимировна (pushkina4@yandex.ru), Кривошлыкова Людмила Владимировна (lvk1404@mail.ru), Шестакова Ксения Александровна (xenia.shestackowa@yandex.ru).

Журнал «Современная наука: актуальные проблемы теории и практики» 